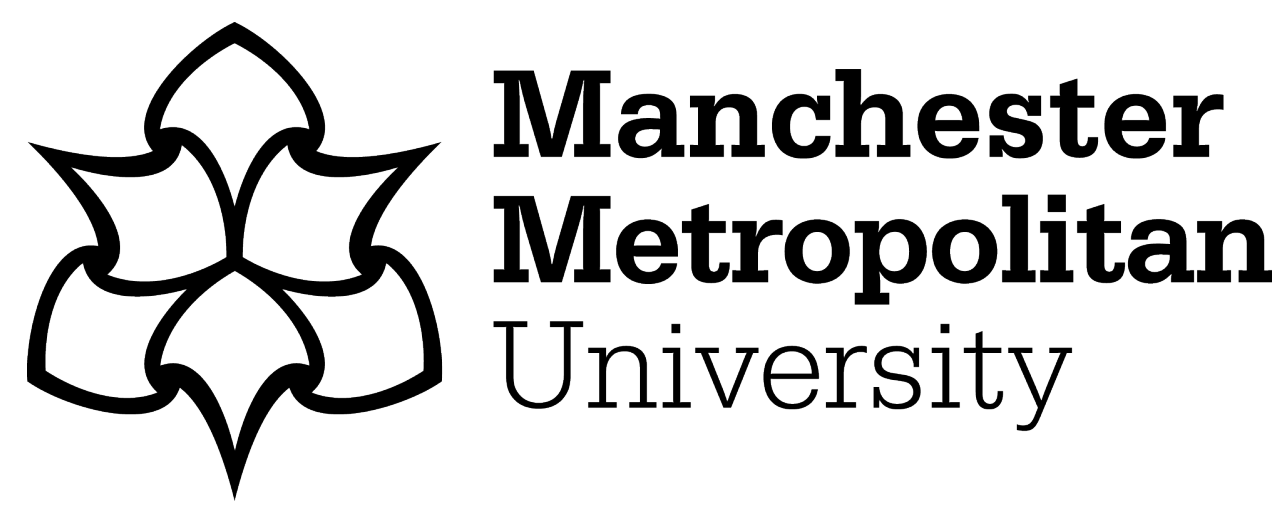

Harrison, I, Pietrosanti, S, Luque, A, Mayer, R and Holderbaum, W (2018) Recording and analysing measurements from an RTG crane. Measurement: Journal of the International Measurement Confederation, 125. pp. 284-293. ISSN 0263-2241

Downloaded from: https://e-space.mmu.ac.uk/620719/

Version: Accepted Version

Publisher: Elsevier

DOI: https://doi.org/10.1016/j.measurement.2018.04.089

Usage rights: Creative Commons: Attribution-Noncommercial-No Derivative Works 4.0

Please cite the published version 


\title{
Recording and analysing measurements from an RTG crane
}

\author{
I. Harrison ${ }^{\mathrm{a}, *}$, S. Pietrosanti ${ }^{\mathrm{a}}$, A. Luque ${ }^{\mathrm{a}}$, R. Mayer ${ }^{\mathrm{b}}$, W. Holderbaum ${ }^{\mathrm{c}}$ \\ ${ }^{a}$ Dept. of Biomedical Engineering, University Of Reading, Reading RG6 6AY, United Kingdom \\ b 9 Heathwood Close, Yateley, Hampshire GU46 7TP, United Kingdom \\ ' School of Engineering, Manchester Metropolitan University, Manchester M1 5QD, United Kingdom
}

A R T I C L E IN F O

Keywords:

Energy reduction

Beckhoff

MATLAB

Graphical user interface

RTG cranes

Power measurement system

Energy storage

Simulations

\begin{abstract}
A B S T R A C T
The paper presents a bespoke power measurement system that has been designed and implemented on a Rubber Tyre Gantry, RTG crane at the Port of Felixstowe, PoF. The design of a novel system topology which is centred around a Beckhoff computer, as well as the specifications of the various transducers used, is detailed. To complement the hardware installation, a bespoke data analysis tool has also been developed in MATLAB, an overview of its operation and use are presented. The system allows for the characterisation of the cranes' various motors during operational hours; furthermore, the data collected has been used to verify simulations of RTGs developed as part of the overall PoF project. The measurement system was installed on RTG1 at the port in March 2016.
\end{abstract}

\section{Introduction}

Transshipment is crucial to international commerce. Shipping ports such as the Port of Felixstowe, play a vital role in this process, allowing goods to be transferred off and on ships and facilitate the travel of goods onwards to the rest of the country. The issue that most ports face is their large energy consumption, and carbon emissions, from the various machines that enable their operation. The energy consumption and carbon emissions of ports in the EU are being targeted by European Commission as part of "Reducing emissions from the shipping sector" initiative [1]. This has forced numerous ports to investigate options for carbon emission reduction. The owner of the PoF and numerous other shipping ports, Hutchison Port Holdings Limited, have set up their own green policy called Go Green [2] to help combat this ever-growing issue. The PoF have also decided to electrify their entire fleet of Rubber Tyre Gantry, cranes (Fig. 1). Investigations carried out by Yang and Chang in 2013 suggest this electrification has dramatic impacts and is able to "achieve $86.60 \%$ energy savings and a $67.79 \%$ reduction in $\mathrm{CO} 2$ emissions" [3]. A multitude of methods for optimising port operations have been researched globally, as reviewed by Stahlbock and Vo [4].

RTGs allow containers to be manoeuvred off and on container stacks from trucks, tugs or straddle carriers. RTGs are typically powered via an on-board diesel generator; the electrification process enables the RTGs to be connected to the local electrical network. In the case of PoF, this is achieved using a VALHE conductor bar which runs the length of the container stack. This can be seen in Fig. 1, the bar resembles a metal fence along the left-hand side of the empty container stack. With this electrification an obvious issue arises, that is the increase in the power demand on the port's local grid. An RTG can consume up to $350 \mathrm{~kW}$ during the initial phase of a lift, and $250 \mathrm{~kW}$ in steady state (based upon a standard lift test with a $30 \mathrm{~T}$ container); it is clear that if multiple RTGs were lifting containers simultaneously, the cumulative power load could significantly increase the demand on the incoming grid supplies.

Port operators can gain benefit from examining the power consumptions of their cranes as they then are able to understand how energy demand directly affects their running costs. Carbon emissions also need to be established to ensure that operators comply with policies like the aforementioned "Reducing emissions from the shipping sector" initiative [1].

Metering and measurement is an important in a number of industries in order to establish where energy can be saved [6]. For instance, many new smart metering devices for the home environment are being developed [7-9]. When examining industrial power and energy metering, O'Driscoll and O'Donnell have published a comprehensive review of the state-of-the-art technologies [6]. To our knowledge, power metering at shipping ports has been examined by a number of authors for examination of carbon reduction [10], for energy reducing technologies [11] and for port infrastructure [12].

Acciaro and Wilmsmeier [13] have stated the following with regards to shipping ports. "Numerous technological solutions are available to reduce energy consumption. However, the uptake of these technologies is often hampered by economic, regulatory, managerial or technical barriers and in general by a lack of financial incentives or of 


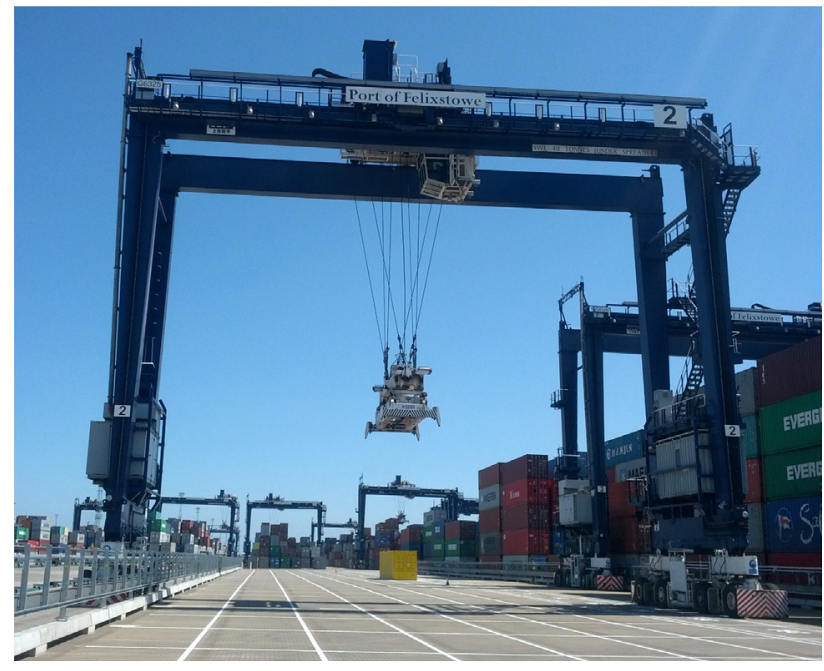

Fig. 1. An RTG crane at the Port of Felixstowe [5].

knowledge. An important issue is the limited availability of high quality data and the lack of information sharing between actors." This was one of PoF's motivations for acquiring data with high precision and high sampling rate.

Previous RTG power measurements made by our group, which led to our previous analysis [14] were all made from data extracted from the crane's on-board PLC. Unfortunately, this method posed a number of issues:

- The power dissipated by the dump resistors was not measured.

- The data for each motor was measured by the motor drives which only recorded the current and voltage. Unfortunately the power factor wasn't recorded hence the active to reactive power ratio was unknown.

- As additional diagnostic equipment from the PoF was used to record this data, the overall dataset was only recorded over 6 days, of which only 4 of the days were usable.

For these reasons a new system was required, and hence this paper describes a bespoke measurement system that has been developed. This novel system not only stores measured power information from the RTGs' various motors, but also interfaces with the RTG's PLC in order to obtain operational information. In conjunction with this measurement system, custom software, which facilitates the analysis of the vast quantity of data, is also presented in this paper.

This paper presents a complete measurement system that will enable researchers and port operators to measure power flows. Furthermore, a data analysis tool interfaces with the measurement system and extracts key indicators from all the metered data. The paper is presented as follows: Section 2 briefly describes the topology of an RTG; Section 3 describes the hardware and installation of the bespoke system; Section 4 introduces the software developed to perform the analysis of the vast quantity of data; Section 5 provides a number of examples of the graphical user interface, GUI's output.

\section{RTG topology}

The RTG on which the measurement system has been deployed at PoF, was manufactured by Shanghai Zhenhua Heavy Industries, ZPMC. The image of an identical model RTG is presented in Fig. 1 and a

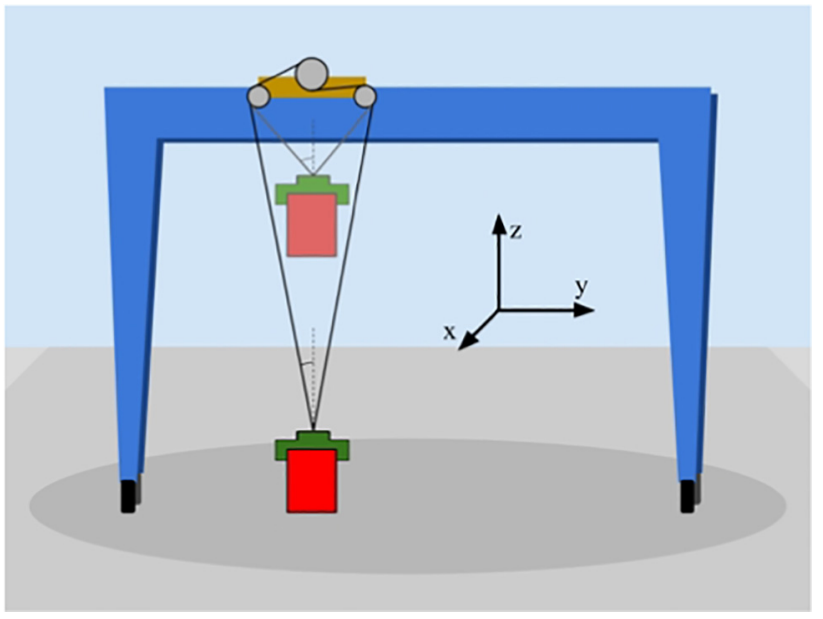

Fig. 2. Diagram of an RTG [14].

simplified overview is given in Fig. 2. An RTG has three main groups of motors, hoist, trolley, and gantry, with reference to Fig. 2 these provide movement in $\mathrm{Z}, \mathrm{Y}$ and $\mathrm{X}$ directions respectively. The hoist motor is used to lift the containers, and the trolley motor allows the container to be traversed, i.e. horizontally moved with respect to crane. Typically, an RTG has four gantry motors, which provide power to each of the RTGs' wheels and thus allows the entire crane to be driven to its required location within the port. In terms of power consumption, the motors can be ranked in the following order, hoist (largest), gantry and trolley (smallest), where the hoist accounts for over a quarter of the overall power consumption of the crane [14]. An electrical overview of how these motors are powered is presented in the following section alongside the metering points for the measurement system (see Fig. 3).

As described earlier, RTGs use their hoist motor to lift containers, using power to perform work against gravity. However, during lowering that same motor acts as a generator to provide electrical braking. This power is typically dissipated as heat through dump resistors, via a fast-acting switch known as a chopper. Technologies such as energy storage systems, ESSs are now under development to reduce the losses in RTGs and are further discussed in Section 7.

In order to manoeuvre the shipping container, a device called a spreader is used, which is attached to the crane and can lock onto the container to allow it to be repositioned. The spreader is aptly named as it can expand and contract in length to accommodate various standard sizes of shipping container, ranging from $20 \mathrm{ft}$ to $45 \mathrm{ft}$ in length. The spreader itself is connected to the RTG with eight cables that are attached to drums on the trolley, which can be seen in Figs. 1 and 2. The trolley is typically where the drivers cabin in situated, providing them with a top down view of the container which can also be seen in Fig. 1 .

\section{RTG measurement system}

The RTG measurement system described in this paper has been devised in order to collect a number of variables that are used to validate simulations of RTGs and understand power flows.

Fig. 3 presents a line overview of the system topology. The measurements were recorded via a Beckhoff CX2020 Programmable Logic Computer, PLC [15]. The Beckhoff PLC is linked (via Ethernet cable) to a Westermo MRD-455 4G router [16], which allows data to be collected remotely. This PLC takes input from the following: 


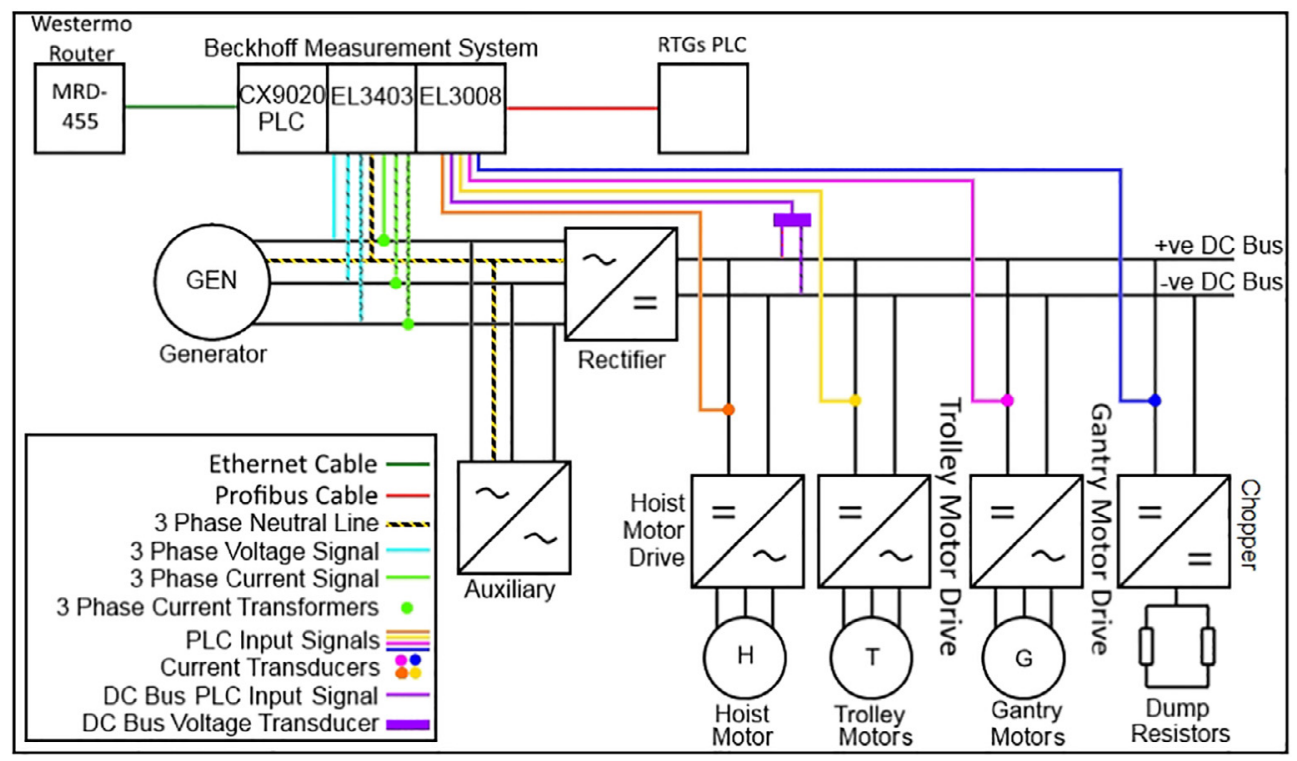

Fig. 3. Line diagram of the hardware installation.

- Power measurement card (Beckhoff part EL3403 [17]), which records the 3 phase input to the crane, i.e. Voltage, Current, Active Power and Power Factor. This amounts to 12 variables, i.e. 4 variables per phase. The current transducers for this power card were already installed on the crane to provide current information to an analogue instrument panel.

- Analogue input card (Beckhoff part EL3008 [18]), which records the DC bus transducer output voltage signals. The following 5 variables were recorded, along with their respective transducers:

- DC Bus Voltage from LEM DVL 750 SP/5 [19].

- Hoist Drive Current from LEM HAX 500-S [20].

- Trolley Drive Current, Gantry Drive Current and Chopper Current each from LEM HTA 300-S [21].

- Profibus interface (Beckhoff part EL6731-0010 [22]) to the RTGs Siemens PLC records in total 19 variables characterising the RTG itself, including:

- Spreader Position: Horizontal and Vertical Position in mm

- Spreader container information: Landed, Locked, Unlocked, Container Length 20, 30, 40, $45 \mathrm{ft}$.

- Hoist and Trolley Motor Speeds in RPM.

- Load Value in tonnes, this value is taken from a load meter situated under the cable reel drum; this provides the gross load value and includes the mass of the spreader, the cable reel and drum $(\sim 12.5 \mathrm{~T}$ in total).

- Hoist, Trolley and Gantry Motor State, i.e. whether the motors are active or not.

- Conductor Bar and Generator State, i.e. whether or not the RTG is being powered by the Bus Bar system or its on-board Diesel generator.

- Current flow to the Rectifier.

- Time from the Crane PLC, this is recorded in order to ensure that the data we receive via profibus is being updated.

The data is sampled at $10 \mathrm{~Hz}$, resulting in 864,000 samples a day, from a total of 37 variables, 12 three phase measurements, 5 DC bus measurements, 19 RTG PLC variables and the Beckhoffs' time stamp, taken from its internal system clock. The data is stored in Comma Separated Variable files, CSV, where each line contains as normal a sample. Due to vast amount of data collected, each of the CSV files store $6 \mathrm{~h}$ worth of data, which prevents the file size from becoming too large. Once a file is complete, the file is transferred from the internal memory of the PLC to USB memory storage; after which the data is then

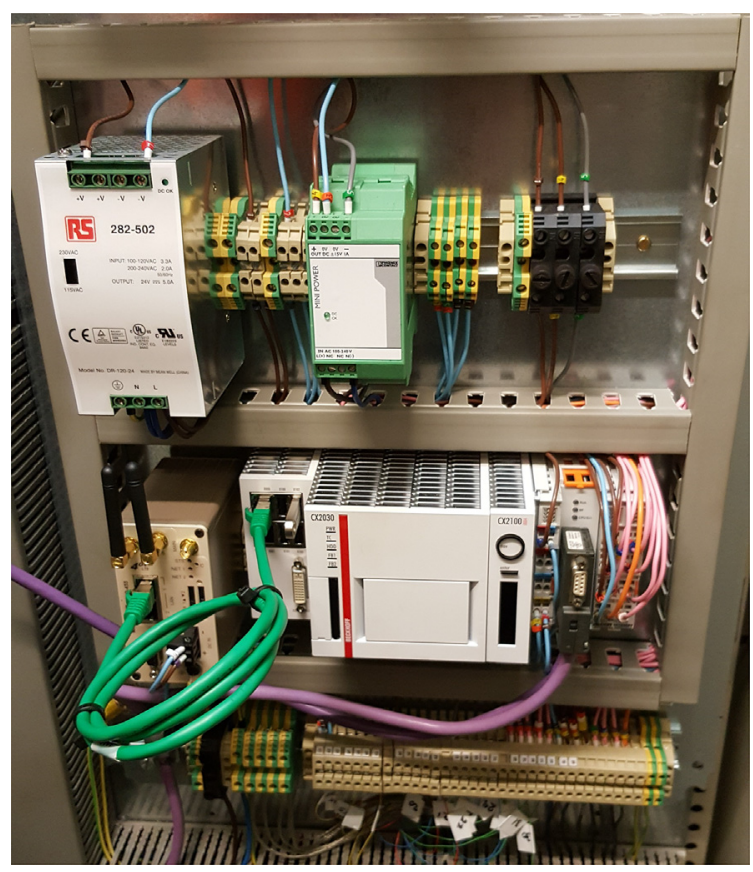

Fig. 4. The installed measurement system.

compressed into a ZIP file. These CSV files are then transferred via the 4G network into a custom GUI created in MATLAB in order to process and analyse the data, which is discussed further in the next section.

This measurement system was installed on RTG1 at the Port of Felixstowe in March 2016. In one year the system has recorded 62.6 GB of data, based on pre-processed data from 1 April 2016, to 1 April 2017, stored as CSV files. Fig. 4 shows the measurement system housed in the e-house of the RTG.

\section{RTG data analysis tool}

The custom GUI created in MATLAB, referred to as the Data Analysis GUI, DAGUI, allows the user to preform various forms of analysis and create a vast number of plots of the collected data. Due to its high versatility, MATLAB is a useful platform for data analysis and creation of bespoke GUIs, for example [23-25]. Before the data is made 

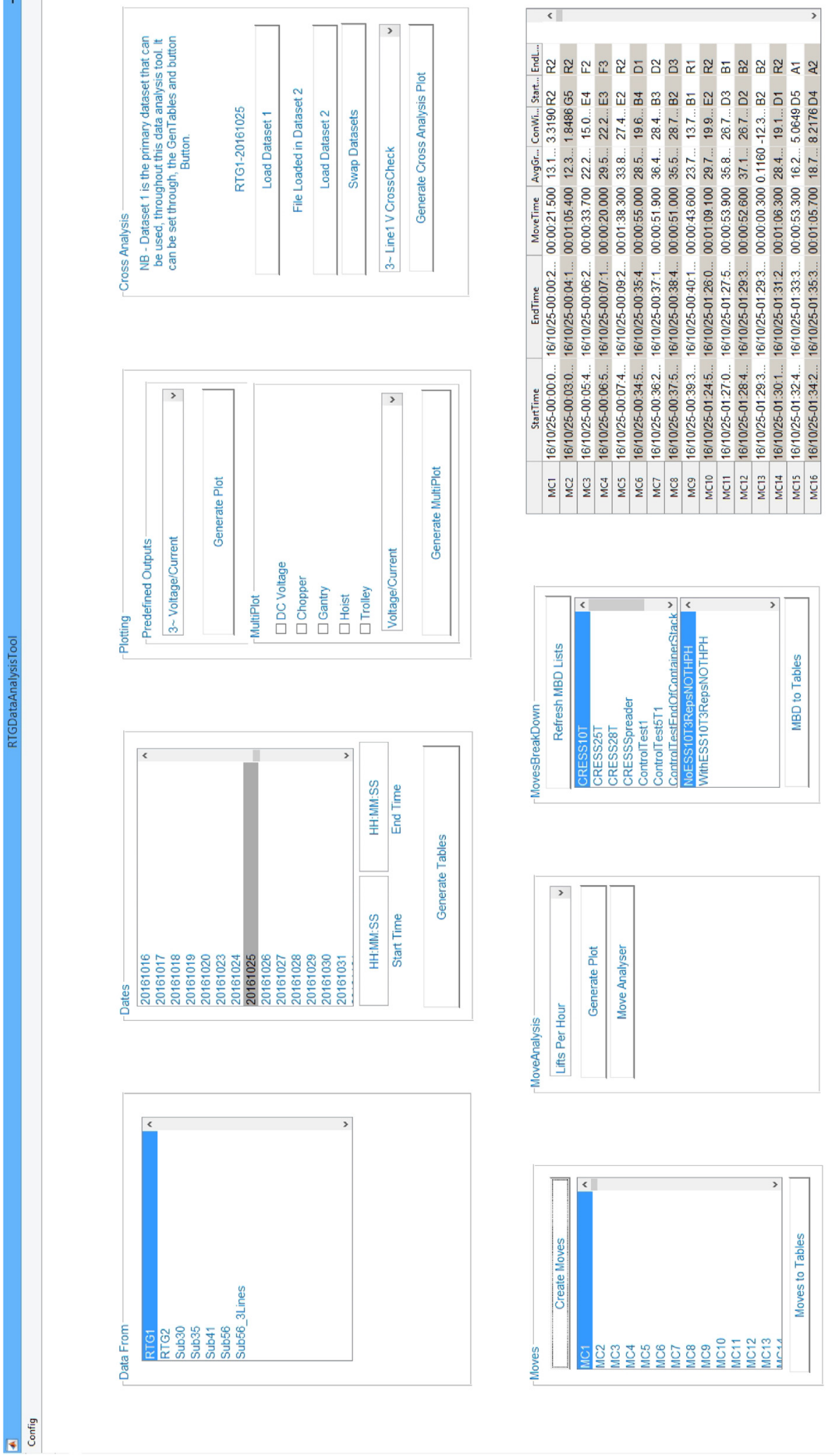

ติ

Fig. 5. The Data Analysis GUI. 


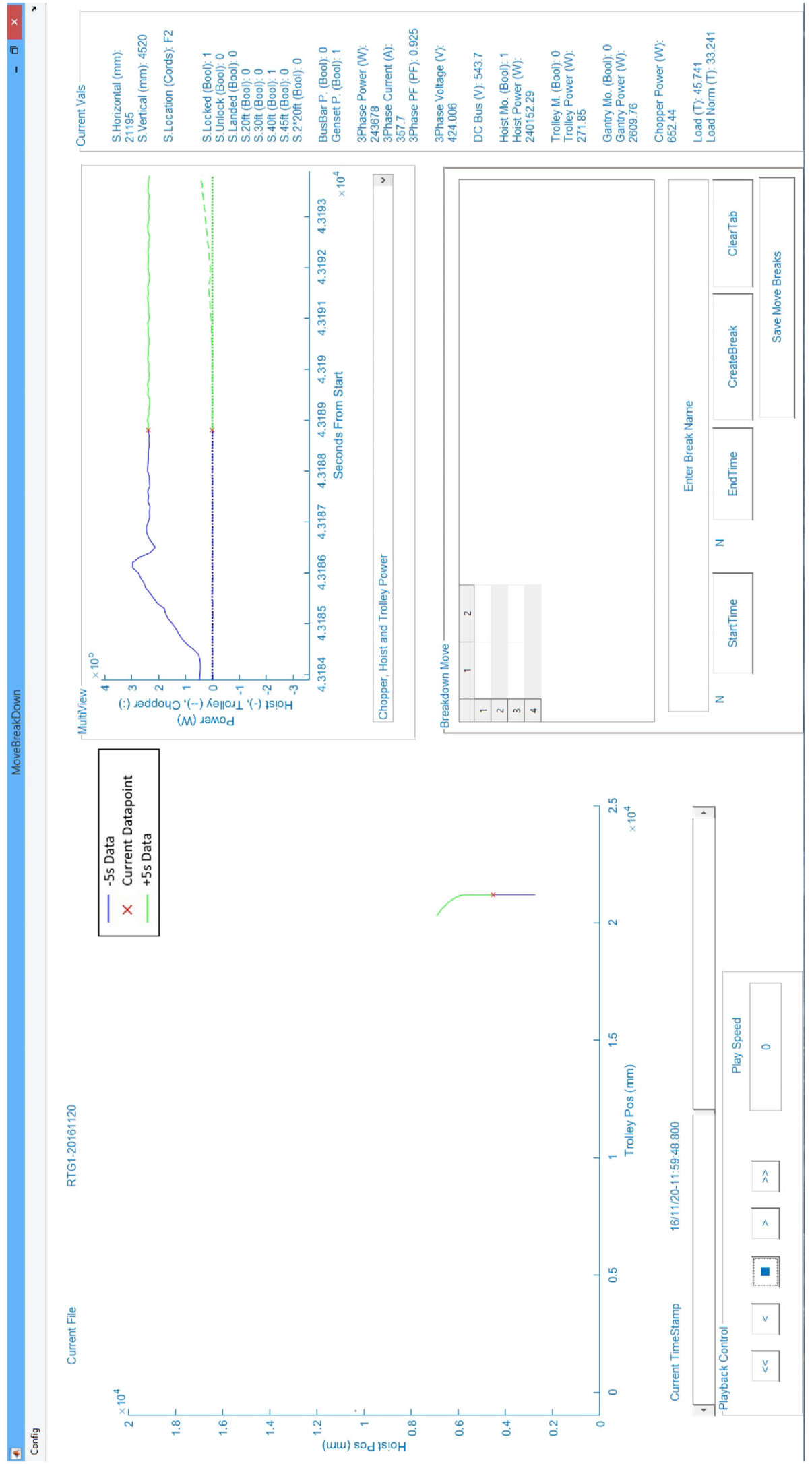

Fig. 6. The Move Break Down GUI. 

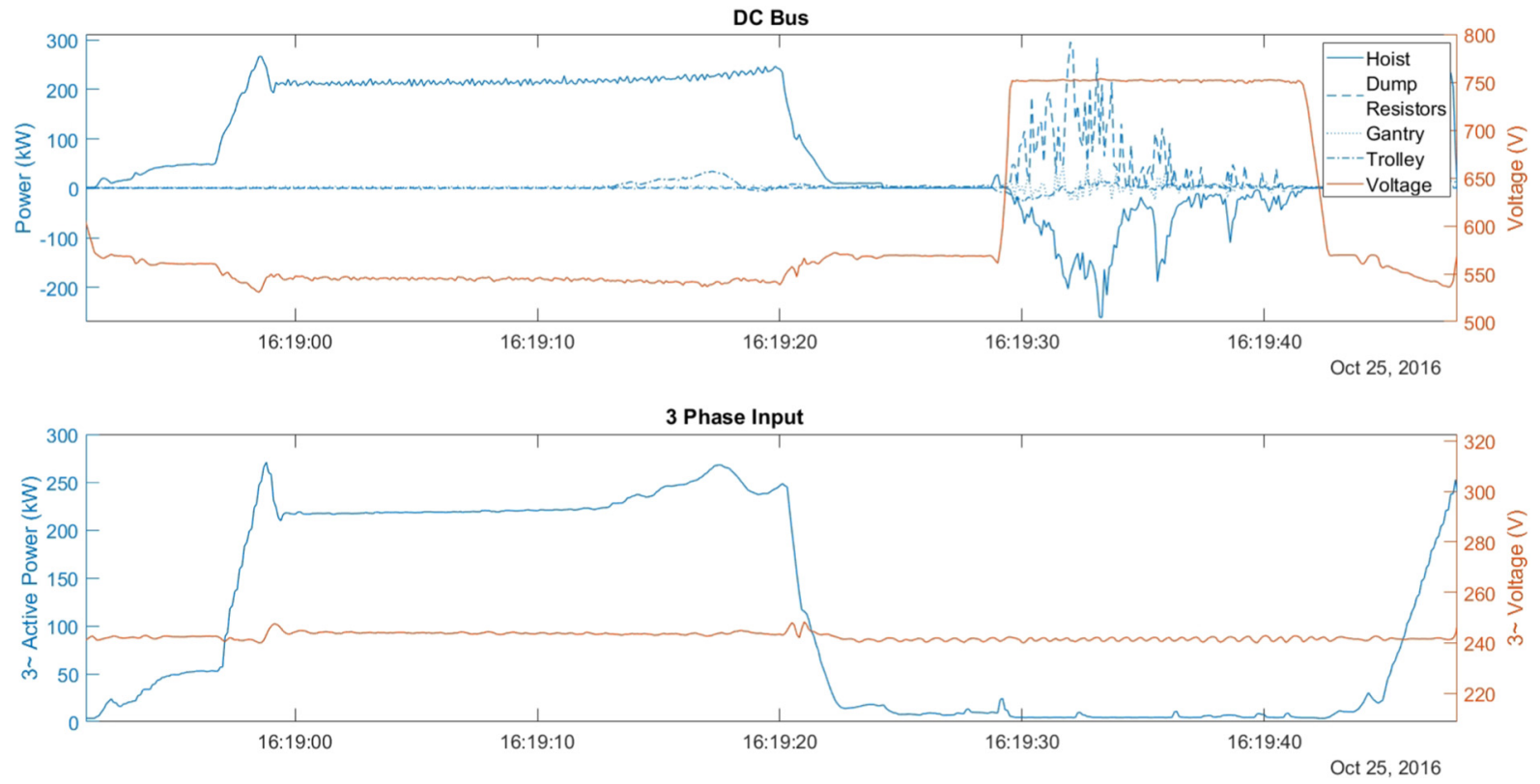

Fig. 7. RTG lift profile example.

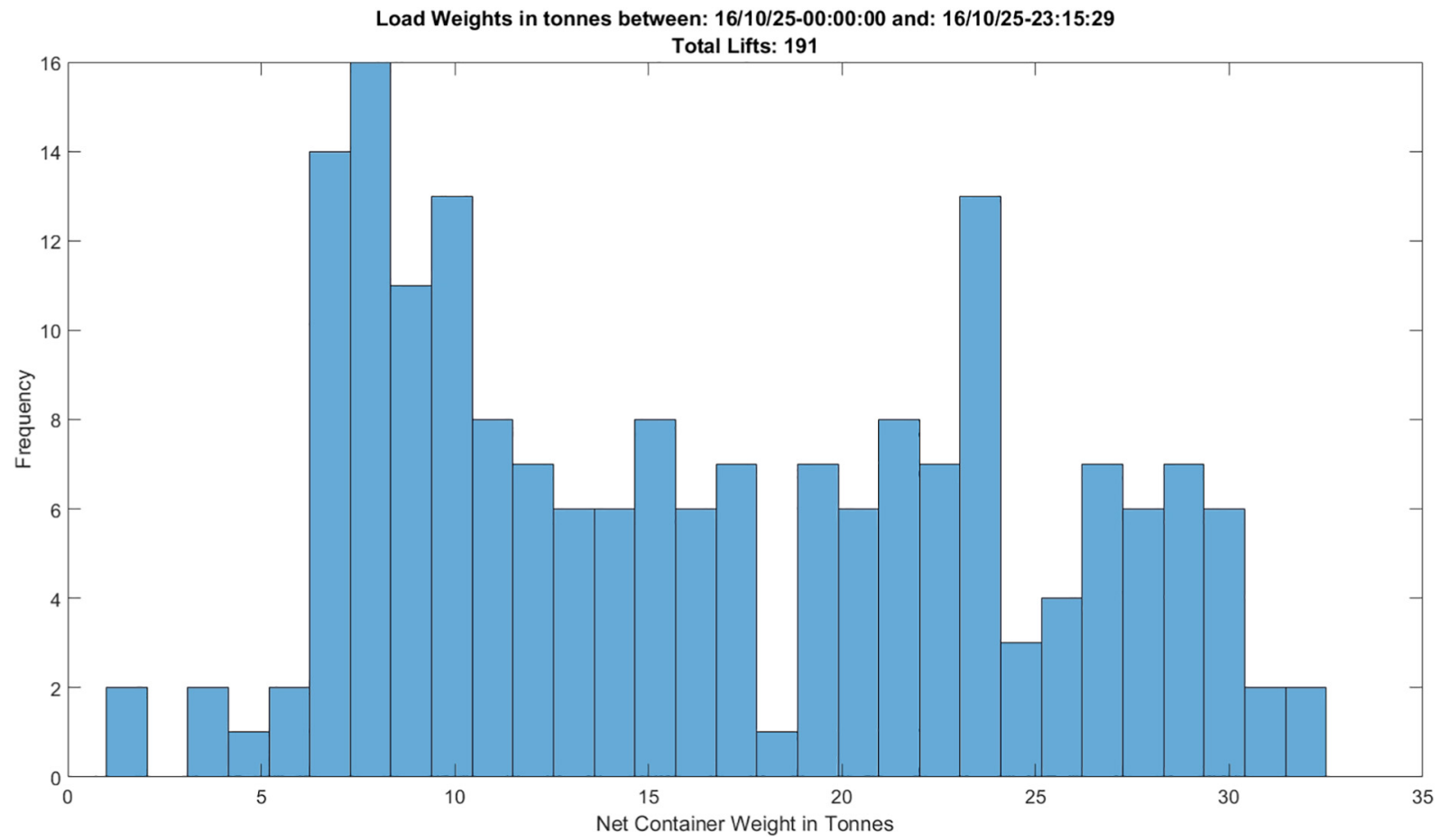

Fig. 8. Distribution of container weights lifted on 25/10/16.

available to the user it is first pre-processed from the CSV files into MATLAB files. This pre-processing involves, linear interpolation on less than 10 missing samples, determining the activity of the crane (off, idle or working), and collating the multiple data files into daily data sets.

Once complete, the user is presented with the GUI shown in Fig. 5. The DAGUI has multiple panels and one table. The purpose of each is as follows:
- Data From Panel - The DAGUI not only receives information from the RTG but from other bespoke metering systems around the Port of Felixstowe. This panel allows the user to select which data source they would like to analyse.

- The Date Panel - This lists the available pre-processed data for the data source selected. The user can select multiple dates as well as set a start and end time of the data to be loaded if required. Finally, the 


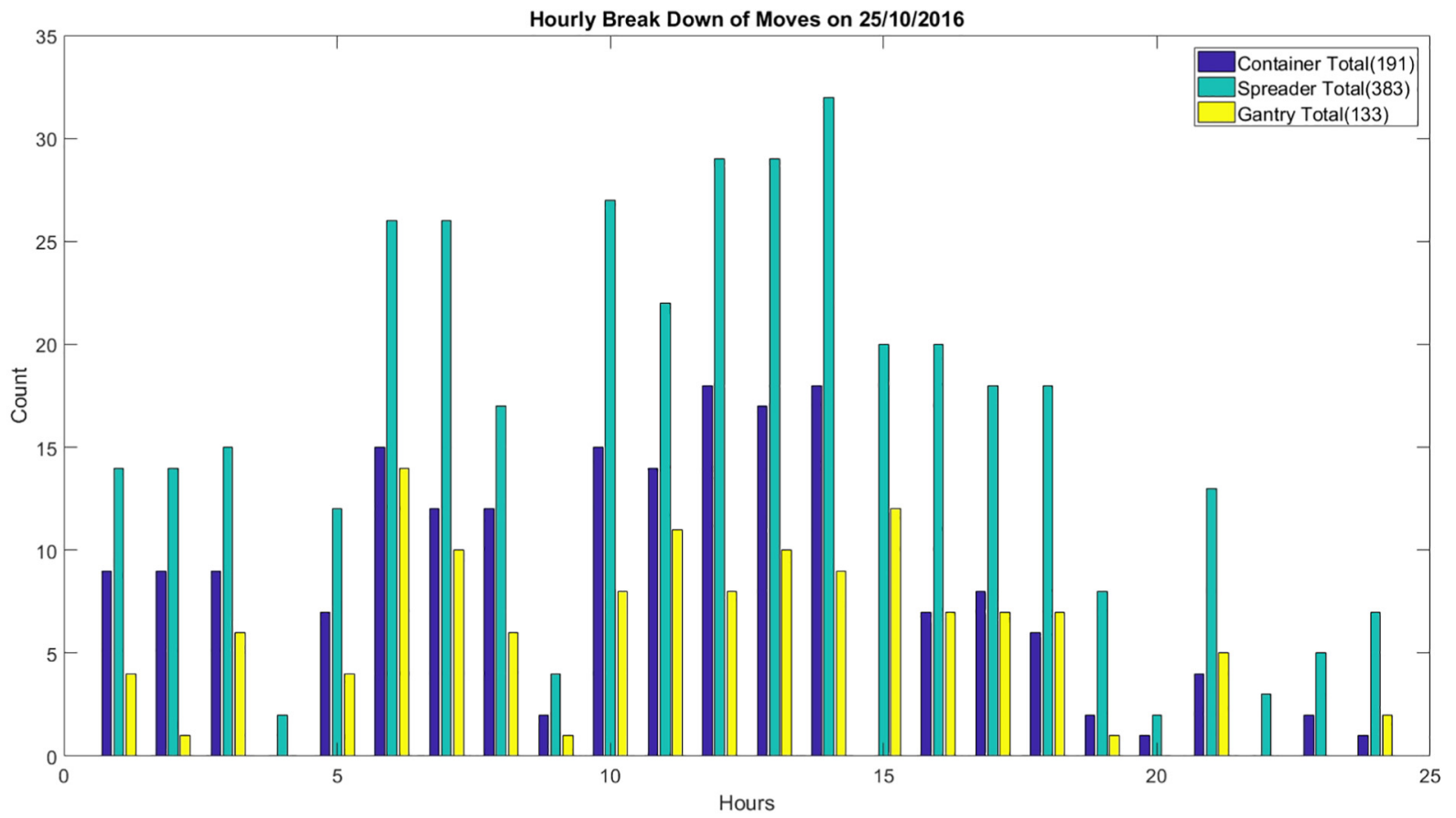

Fig. 9. Distribution of the different moves by hour on 25/10/16.

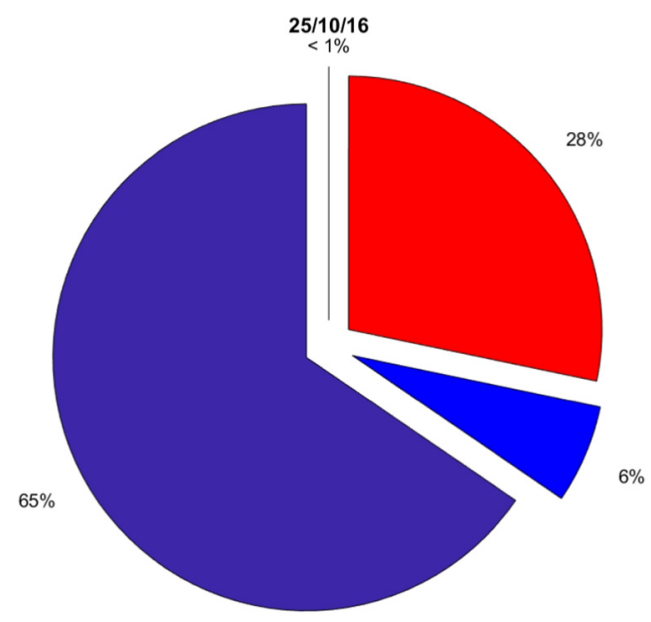

Idle High DC Bus $\square$ Idle Low DC Bus $\square$ Working $\square$ Off

Fig. 10. RTG activity summary on 25/10/16.

user then loads in the data from the selected files by pressing Generate Tables. Having all of the measured data available but not loaded, into system memory ensures that the DAGUI responds rapidly.

- The Plotting Panel - This lists a vast number of the predefined plots and analysis that can be performed on the data, examples of which are presented in Section 5.

- The Cross Analysis Panel - This allows the user to cross examine two data sources; for instance, if the user wishes to compare the power required for performing the same RTG movement on two different container weights.

- The Moves Panel - This panel allows the user to Create Moves, this algorithm searches the day's data to locate three types of movements: container, spreader and gantry. Once this process is complete, the list of moves is presented to the user in the list box as well as in the table positioned in the bottom right of the DAGUI. The table summarises the information about the moves, providing: the move ID (automatically generated, chronologically based); the start, end and elapsed time; the start and end position; and the container weight in tonnes.

- The Move Analysis Panel - This allows the user to analyse information from a single move, taken from a list of all the moves detected. This information, like container weight and time taken to complete the move, is displayed as histograms. Examples of which are presented in Section 5. The Move Analyser button launches a second custom GUI called the Move Break Down GUI, MBDGUI, shown in Fig. 6, which is further explained below.

- The Moves Break Down Panel - This allows the user to select data categorised by the MBDGUI, explained below.

The MBDGUI allows the user to examine data in order to explore particular moves, or oddities in the data. For instance, if the Create Moves function registered a container move that was greater than $5 \mathrm{~min}$, the user can examine what occurred with respect to all of the variables collected. The main function of this GUI is to allow the user to manually categorise the data they are observing so that they can analyse it later in the DAGUI. As shown in Fig. 6 the main focus of the MBDGUI is the location of the spreader and its current trajectory; moreover, the user can play through the data and observe the spreader's movement. This GUI allows the user to then examine all of the other measured variables, which are also played through (see Video 1). For example, the power drawn by the hoist, trolley and dump resistors, as shown in the Multiview panel in Fig. 6. For example, in the case of the greater than $5 \mathrm{~min}$ move mentioned previously, the user might wish to label the first $30 \mathrm{~s}$ as a lift, the next $10 \mathrm{~s}$ as a traverse, then a waiting period, then the final $30 \mathrm{~s}$ as a lower. 


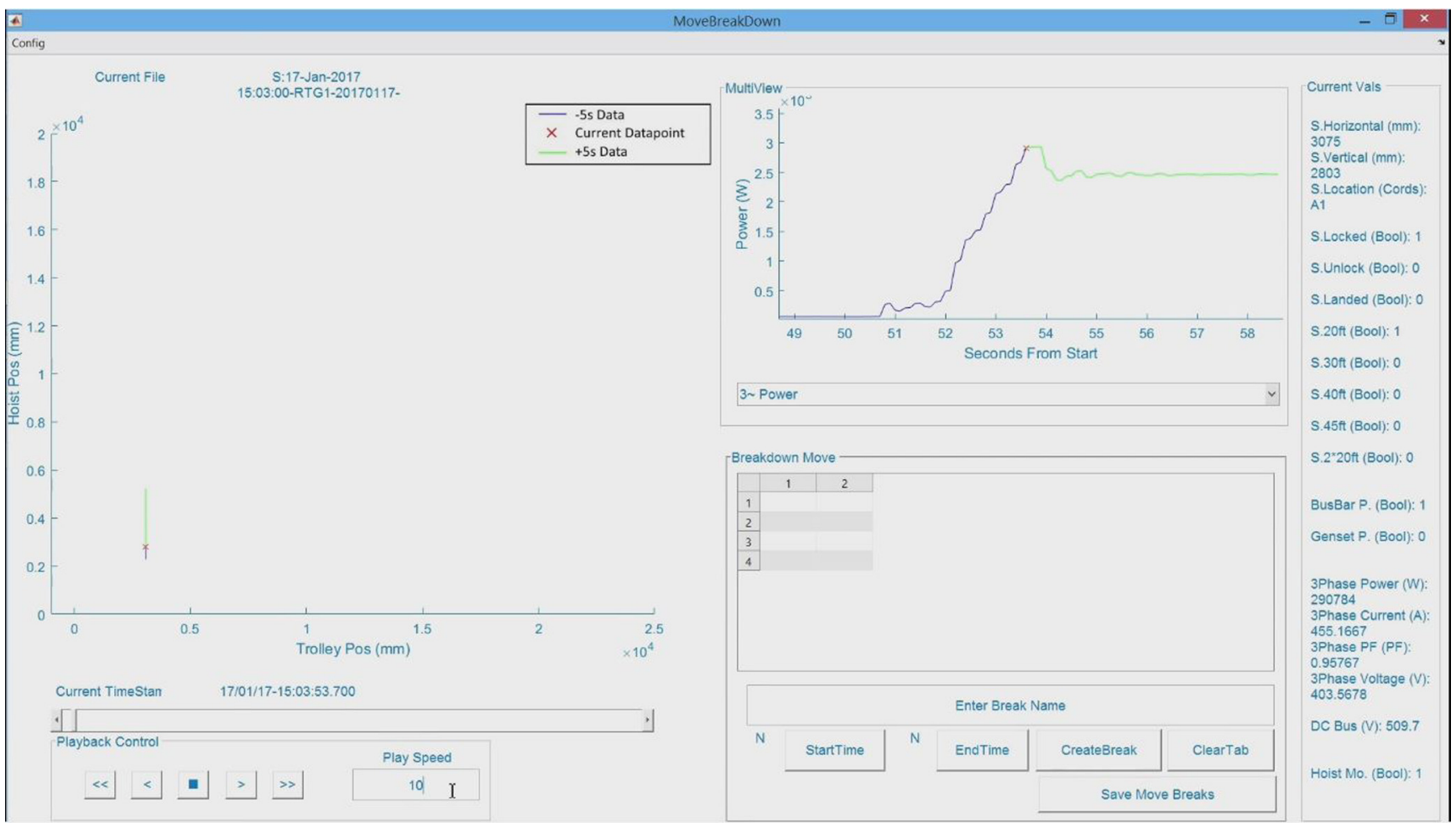

Video 1.

\section{Testing and results}

As previously mentioned the DAGUI allows the user to produce a vast number of plots, tabulations and analysis on the data from the Plotting and Move Analysis panels. Examples are presented below.

The user can create line plots to examine the power flows within the RTG. For example, Fig. 7 (bottom) presents the 3-phase active power input to the RTG during a container move. Fig. 7 (top) examines the power flows during the same movement to and from each of the systems on the DC bus, i.e. the hoist, trolley and gantry motors, as well as the dump resistors. Plots such as this can be used to characterise the RTG during certain operating conditions, and container movement as they facilitate the overall understanding of power consumption of the crane. Further analysis of these graphs is omitted here as it is not within the scope of this paper.

Analysis plots such as histograms and pie charts can also be easily generated. The histogram in Fig. 8 displays the distribution of the container weights by the RTG on 25/10/16.

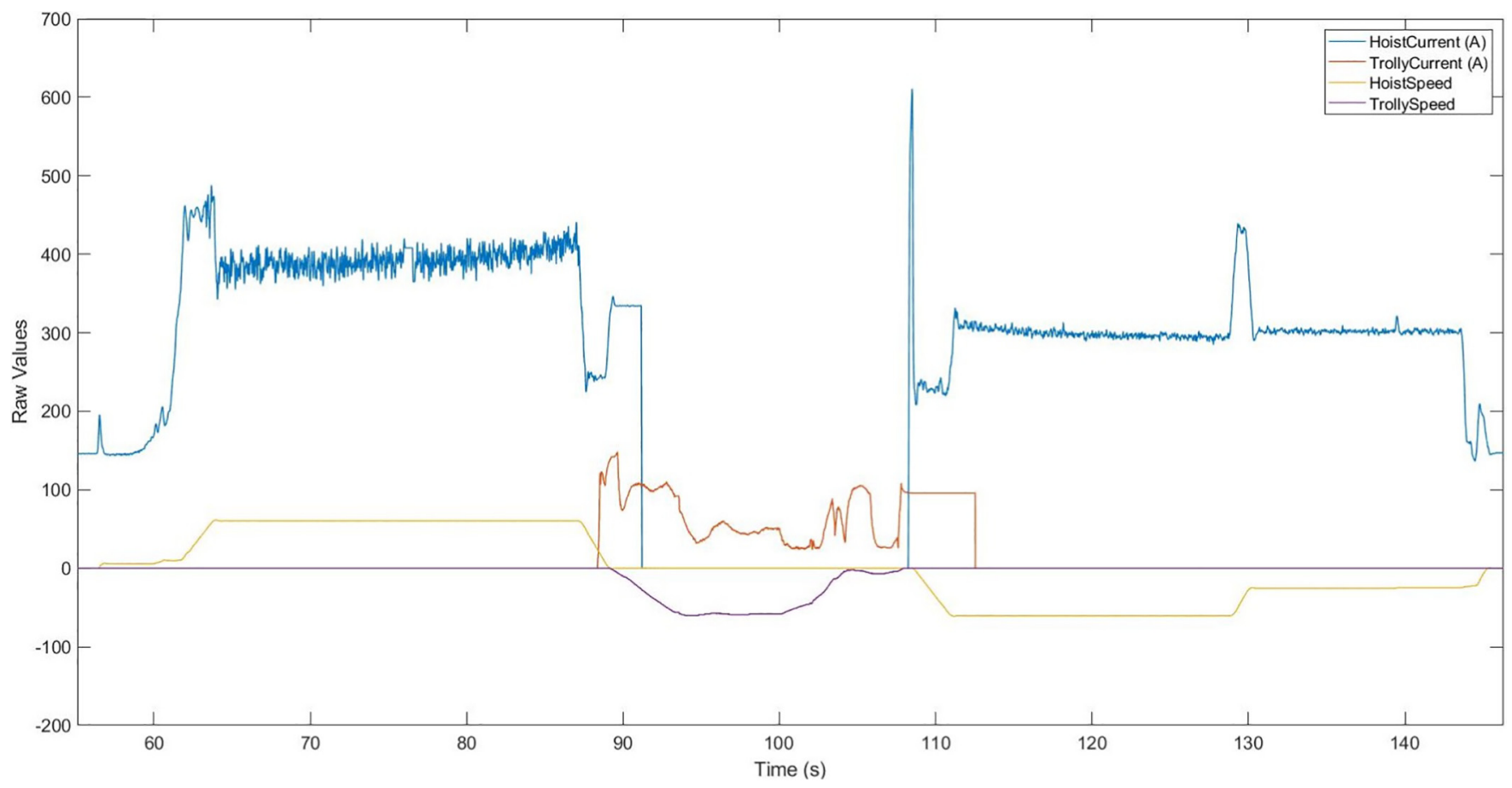

Fig. 11. RTG lift profile example from original data measurements. 
The bar chart in Fig. 9 displays the distribution of the different moves by hour performed by the RTG on 25/10/16.

The pie chart in Fig. 10 displays the activity summary of RTG on 25/ 10/16. In this case idle is separated into high DC Bus [voltage] and low DC bus [voltage], this indicates whether the DC rectifier was on or off, i.e. whether the motor drives were on or just the crane's auxiliaries.

\section{Discussion}

The objective of this work was to accurately understand the power flows of an RTG crane during typical operating conditions.

The Beckhoff PLC was chosen for this implementation due its price, ease of use, and moreover the vast amount of interfacing offered by one system; i.e. interfacing to the cranes PLC via profibus, as well as the various DC and 3 phase voltage and current transducers. Furthermore, through programming the device, a multitude of factors have been controlled including, the measurement sample rate, data storage method, the record layout. This has allowed for greater flexibility from the system.

The DAGUI was devised to allow all members of the research group efficient access to the vast amounts of data. The PoF project has benefited greatly as a result of this, as DAGUI performed all of the necessary pre-processing, and allowed the users' rapid access to a multitude of plots and metrics. The functionality of the DAGUI continues to increase as the research progresses and the analysis requirements expand.

As stated previously, the data collected by our team initially, analysed in [14], was recorded from the crane's on-board PLC. The hoist motor current was measured in the drive itself (i.e. 3 phase current) which is insufficient to quantify the power. This was due to a lack of power factor measurement, and thus energy usage and regeneration from the hoist motor could not be quantified. The hoist current from the drives was also measured as absolute values, hence the requirement of the drive speeds to ascertain direction of travel. This was also the same for the trolley current measurement, however the difference in power usage in a given direction seems negligible. Finally, the actual dissipated power through the dump resistors was not measured and therefore the losses of the system could not be attained. An example of the previous data measurements is given in Fig. 11, which shows a movement profile similar to that in Fig. 7.

In comparison the new system measures the current and voltage on the DC bus prior to the hoist motor drive. This allows for power to be correctly determined and therefore energy usage to be calculated. Furthermore, the dump resistors' power is measured prior to the chopper again by measuring current and voltage on the DC bus, allowing for the system losses to be quantified.

\section{Conclusion}

In this paper a bespoke power measurement system for an RTG crane has been presented. The hardware of the system is centred around a Beckhoff PLC and the software to assist in the data analysis was developed in MATLAB. The measurement system was installed on an RTG at the PoF in March 2016. Since its installation it has continued to record power flow measurements during times of operation. The purpose of this measurement system was to further understand the power flows of an RTG under operational conditions as well as to verify and use as part of simulations of RTG cranes [5,26-32]; on both accounts the system has proven to be successful.

Technologies such as Energy Storage Systems, ESSs, are now becoming available, in order to harness the otherwise wasted energy generated by an RTGs' hoist motor when a container is lowered. One such system is currently under development by a company called CRESS. Their ESS will be positioned on-board the RTG harvesting otherwise wasted energy during lowering of a container and using it to compensate the power demand of sequential lifts. The CRESS ESS is flywheel based, which has also been examined by Flynn et al. [11,33]. Flywheels are not the only type of ESS technology being examined for this application, batteries and super capacitor based systems, as well as hybrid solutions are also under investigation and implementation [34-36]. Another solution to utilise this otherwise dissipated energy on an electric RTG is to modify the pre-existing power system to include an active front end, such that the power can be regenerated back into the local grid. This measurement system and DAGUI can be used to quantify the benefits of these technologies.

Simulations of machinery such as RTGs allow for the benefits of additional systems to be evaluated prior to installation [26,27]. In this case the benefits of ESSs can be examined, and to establish their benefits without the fiscal implications of modifying the crane and so, simulations and modelling of both the RTG and ESS are important. Thus, an RTG measurement system has been developed, as models are inconsequential without real world measurements to validate them.

\section{Acknowledgements}

This research was undertaken as part of the Susports Project which was funded by Climate KIC. This study could not have been undertaken without the cooperation of the Port of Felixstowe and we wish to acknowledge the support of Jim Alsop, Chris Codling, Tony Isherwood, Clive Lavery, Ian Martin, Paul Mathews, Wayne Travis, Simon Wiggins; the support of Joshua Butler, Dan O'Sullivan, Phil Wright of Needham Electrical; the support of Pam Lewis of Sciotech; the support of Simeon Adejumo, Alec Chetcuti, Dan Hope, and Nicholas Warren of the University of Reading.

\section{References}

[1] EU Commission, Reducing Emissions from the Shipping Sector. URL $<$ https://ec. europa.eu/clima/policies/transport/shipping_en > , 2017 (accessed: 8/8/17).

[2] Hutchison Port Holdings Limited, Go Green About US. URL $<$ https://green. hutchisonports.com/features/about_us/ > , 2016 (accessed: 8/8/17).

[3] Y.C. Yang, W.M. Chang, Impacts of electric rubber-tired gantries on green port performance, Res. Transport. Bus. Manage. 8 (2013) (2013) 67-76, http://dx.doi. org/10.1016/j.rtbm.2013.04.002.

[4] R. Stahlbock, S. Voß, Operations research at container terminals: a literature update, OR Spectrum 30 (1) (2008) 1-52, http://dx.doi.org/10.1007/s00291-0070100-9.

[5] S. Pietrosanti, W. Holderbaum, V.M. Becerra, Optimal power management strategy for energy storage with stochastic loads, Energies 9 (3) (2016) 1-17, http://dx.doi. org/10.3390/en9030175.

[6] E. O'Driscoll, G.E. O'Donnell, Industrial power and energy metering - a state-of-theart review, J. Cleaner Prod. 41 (2013) 53-64, http://dx.doi.org/10.1016/j.jclepro. 2012.09.046.

[7] D. Sobya, S.K. Muruganandham, S. Nallusamy, P.S. Chakraborty, Development of Bluetooth based smart meter reading system for residential power monitoring, Int J. Rec. Res. Sci. Eng. Technol. (IJRRSET) 5 (12) (2017) 39-47.

[8] R. Anand, G.R. Kanagachidambaresan, M. Balaji, K.S. Chandragupta Mauryan, Design of smart meter for smart grid application through true time - MATLAB, in International Conference on Electrical, Instrumentation and Communication Engineering (ICEICE), 2017, pp. 1-3. http://dx.doi.org/10.1109/ICEICE.2017. 8191846.

[9] A. Kaur, S. Manwinder, Design a low power Zigbee based smart energy metering, Int. J. Eng. Comput. Sci. 6 (9) (2017) 22416-22424, http://dx.doi.org/10.18535/ ijecs/v6i9.04.

[10] B. Pavlic, F. Cepak, B. Sucic, M. Peckaj, B. Kandus, Sustainable port infrastructure, practical implementation of the green port concept, Therm. Sci. 18 (3) (2014) 935-948, http://dx.doi.org/10.2298/TSCI1403935P.

[11] M. Flynn, P. Mcmullen, O. Solis, Saving energy using flywheels, IEEE Ind. Appl. Mag. 14 (6) (2008) 69-76, http://dx.doi.org/10.1109/MIAS.2008.929351.

[12] T. Tran, S. Nahavandi, R. Reid, Design of electrical infrastructure at container terminal and 'net metering', in: PQ 2008: 6th International Conference - 2008 Power Quality and Supply Reliability, Conference Proceedings, vol. 1, 2008, pp. 37-40. http://dx.doi.org/10.1109/PQ.2008.4653734.

[13] M. Acciaro, G. Wilmsmeier, Energy efficiency in maritime logistics chains, Res. Transport. Bus. Manage. 17 (2015) 1-7, http://dx.doi.org/10.1016/j.rtbm.2015.11. 002.

[14] V. Papaioannou, S. Pietrosanti, W. Holderbaum, V.M. Becerra, R. Mayer, Analysis of energy usage for RTG cranes, Energy 125 (2017) 337-344, http://dx.doi.org/10. 1016/j.energy.2017.02.122.

[15] Beckhoff, CX2020-Basic CPU Module. URL < https://www.beckhoff.com/english. asp?embedded_pc/cx2020.htm > , 2017 (accessed: 8/8/17).

[16] Westermo, Industrial mobile broadband/ 4G Router. URL < http://www.westermo. 
co.uk/web/web_en_idc_uk.nsf/alldocuments/

1B42DB6916414004C1257DDD004BC3D1 >, 2017 (accessed: 8/8/17).

[17] Beckhoff, EL3403-3-Phase Power Measurement Terminal. URL < http://www. beckhoff.co.uk/english.asp? ethercat/el3403.htm > , 2017 (accessed: 8/8/17).

[18] Beckhoff, EL3004, EL3008-4-, 8-Channel Analog Input Terminals -10... 10 V, Single-ended, 12 Bit. URL < https://www.beckhoff.com/english.asp?ethercat/ el3004_el3008.htm > , 2017 (accessed: 8/8/17).

[19] LEM, DVL Voltage. URL < http://www.lem.com/hq/en/component/option,com catalog/task,displayserie/serie,DVLvoltage/output_type,/ > , 2017 (accessed: 8/ 8/17).

[20] LEM, HAX 500-s. URL < http://www.lem.com/hq/en/component/option,com catalog/task,displaymodel/id,64.75.50.000.0/ > , 2017 (accessed: 8/8/17).

[21] LEM, HTA 300-s. URL < http://www.lem.com/hq/en/component/option,com_ catalog/task, displaymodel/id,60.63.46.000.4/ > , 2017 (accessed: 8/8/17).

[22] Beckhoff, EL6731—PROFIBUS Master/Slave Terminal. URL < https://www. beckhoff.com/english.asp?ethercat/el6731.htm > , 2017 (accessed: 8/8/17).

[23] R. Gupta, J.N. Bera, M. Mitra, Development of an embedded system and MATLABbased GUI for online acquisition and analysis of ECG signal, Meas.: J. Int. Meas. Confederation 43 (9) (2010) 1119-1126, http://dx.doi.org/10.1016/j. measurement.2010.05.003.

[24] E.N. Sokos, J. Zahradnik, ISOLA a Fortran code and a Matlab GUI to perform multiple-point source inversion of seismic data, Comput. Geosci. 34 (8) (2008) 967-977, http://dx.doi.org/10.1016/j.cageo.2007.07.005.

[25] B. Tibor, V. Fedak, F. Durovský, Modeling and simulation of the BLDC motor in MATLAB GUI, in: Proceedings - ISIE 2011: 2011 IEEE International Symposium on Industrial Electronics, 2011, pp. 1403-1407. http://dx.doi.org/10.1109/ISIE.2011. 5984365.

[26] S. Pietrosanti, I. Harrison, A. Luque, W. Holderbaum, V.M. Becerra, Net energy savings in Rubber Tyred Gantry cranes equipped with an active front end, in: EEEIC 2016 - International Conference on Environment and Electrical Engineering. http://dx.doi.org/10.1109/EEEIC.2016.7555814.

[27] A. Luque, I. Harrison, S. Pietrosanti, F.M.M. Alasali, W. Holderbaum, R.M. Mayer,
V.M. Becerra, Energy reduction on eRTG, in: EEEIC 2016 - International Conference on Environment and Electrical Engineering, 2016, pp. 1-6. http://dx.doi.org/10. 1109/EEEIC.2016.7555446.

[28] F. Alasali, S. Haben, V. Becerra, W. Holderbaum, Analysis of RTG crane load demand and short-term load forecasting, Int. J. Comput. Commun. Instrum. Eng. 3(2). http://dx.doi.org/10.15242/IJCCIE.EAP1216012.

[29] F. Alasali, A. Luque, V. Becerra, W. Holderbaum, Energy reduction and peak shifting on a network of cranes, in: International Conference on Energy, Environment and Economics, vol. 3, 2016, pp. 137-143.

[30] F. Alasali, S. Haben, V. Becerra, W. Holderbaum, Optimal energy management and MPC strategies for electrified RTG cranes with energy storage systems, Energies 10 (1598) (2017) 1-18, http://dx.doi.org/10.3390/en10101598.

[31] F. Alasali, S. Haben, V. Becerra, W. Holderbaum, Peak power reduction for electrified Rubber-Tyred Gantry ( RTG ) cranes using energy storage, in: International Symposium on Automatic Control, 2017, pp. 1-8.

[32] F. Alasali, S. Haben, V. Becerra, W. Holderbaum, A peak shaving solution for electrified Rtg cranes, Int. Acad. Sci. Technol. Eng. Manage. 70 (August) (2012) 35-40.

[33] M. Flynn, P. McMullen, O. Solis, High-speed flywheel and motor drive operation for energy recovery in a mobile gantry crane, in: IEEE Applied Power Electronics Conference and Exposition - APEC, 2007, pp. 1151-1157. http://dx.doi.org/10. 1109/APEX.2007.357660.

[34] C. Chang, J. Yang, P. Cao, Q. Niu, Z. Zhu, Study on supercapacitor energy saving system for Rubber-Tyred Gantry Crane, in: Asia-Pacific Power and Energy Engineering Conference, APPEEC (1). http://dx.doi.org/10.1109/APPEEC.2010. 5448850.

[35] W. Niu, X. Huang, F. Yuan, N. Schofield, L. Xu, J. Chu, W. Gu, Sizing of energy system of a hybrid lithium battery RTG crane, IEEE Trans. Power Electron. 8993 (c) (2016) 1, http://dx.doi.org/10.1109/TPEL.2016.2632202.

[36] M. Antonelli, M. Ceraolo, U. Desideri, G. Lutzemberger, L. Sani, Hybridization of rubber tired gantry ( RTG ) cranes, J. Energy Storage 12 (2017) 186-195, http://dx. doi.org/10.1016/j.est.2017.05.004. 